\title{
Henrik Gottlieb, Jens Erik Mogensen (eds) 2007. Dictionary Visions, Research and Practice (Terminology and Lexicography Research and Practice 10). Amsterdam/Philadelphia: John Benjamins, xi + 321 pages. ISBN 978902722334 .
}

The concept of dictionary vision is frequently used when we speak about lexicography. Since the late 1980s, we have been witnesses to the consolidation of lexicography as an academic discipline, which, firstly, has helped in compiling better dictionaries meant to fulfil the needs of specific user groups, and, secondly, has focused its object of study on dictionaries. As always happens in any academic discipline, lexicography has also been subject to different controversies regarding its nature, methods of works, objectives, etc. The different theoretical approaches to dictionaries are usually present in any lexicography conference, symposium, workshop, etc. They are also found in this volume, a collection of papers discussed at the Twelfth International Symposium on Lexicography celebrated at the University of Copenhagen, April 29-May 1, 2004. The volume presents 19 selected papers covering a wide field within lexicography: (i) online lexicography; (ii) dictionary structure; (iii) phraseology in dictionaries; (iv) LSP lexicography; (v) etymology, history and culture in lexicography. In the Preface, Gottlieb and Mogensen indicate that the 19 papers selected, 15 of which are in English, have been anonymously peer-reviewed and selected according to quality, relevance, and variety of approaches and topics. Among them are the three plenary lectures given by Arne Zettersten, founding father of the symposium, Henning Bergenholtz and Sven Tarp, and Herbert Ernst Wiegand, who have laid the foundations for drawing the line between lexicography and other disciplines, particularly linguistics, although maintaining between them deep differences on both theoretical and practical grounds (see Bergenholtz/ Tarp 2003 for an overview).

Part 1 contains three chapters concerning Online Lexicography. In Chapter 1, "reliability of online bilingual dictionaries" (3-12), Cristina Gelpí proposes a selection of main features of online bilingual dictionaries, defends that online bilingual dictionaries are specific products, different from printed dictionaries, and illustrates her visions with examples from online specialized bilingual English-Spanish dictionaries. She concludes that in addition to coverage, online dictionary quality can be determined by factors such as web page origin, user type, adaptation to lexicographical functions, data-accessing system, lexicographical structures, usability, permanence and updating, degree of digitalization and hypertextuality, and permeability and interaction.

Annette Klosa and Carolin Müller-Spitzer deal with grammatical data in "Grammatische Angaben in elexiko und ihre Modellierung" (13-37). The project 


\section{8}

elexiko is described as the first German hypertext dictionary to be compiled on a corpus basis. It provides not only an improved quantity of lexical information, but also a new quality of information which will be explained and illustrated at different levels of the microstructure of the dictionary. Regarding grammatical data, this paper illustrates how they are arranged content-wise depending on corpus data, and how they were modelled.

Finally, Wlodzimierz Sobkowiak refers in chapter 3 to phonetic interfaces. In his paper "Innovative phonetic interfaces for electronic dictionaries" (39-52), Sobkowiak defends that innovative interfaces are the right answer to new dictionary lookup habits of "the highly computer-savvy generation" (50). He claims that adding pull-down menus to standard interfaces will not do, either pedagogically or commercially. Instead of them, his vision appeals for the application of innovative graphical user interfaces (GUIs), such as developments made by the makers of KirrKirr and Visual Thesaurus, both available online (http://www-nlp.stanford.edu/kirrkirr/ausweb99/present.html and http://thesaurus.plumbdesign.com/index.jsp, respectively), to ordinary semasiological electronic dictionaries. He concludes by making two safe predictions: innovative graphical user interfaces will be firstly applied to a learner's dictionary of English as a foreign language; pronunciation will be the last to benefit from this breakthrough in GUI design.

Part 2, which consists of chapters 4 and 5 by Rufus H. Gouws and Andrejs Veisbergs respectively, analyzes Dictionary Structures. In "Sublemmata or main lemmata. A critical look at the presentation of some macrostructural elements" (55-69), Gouws focuses on the need for a critical approach to the macrostructural positioning of lexical items. In his views, this approach should not be based on established lexicographic traditions (for example, the use of main and sublemmata as two major types of lemmatization); rather, he defends that the macrostructural positioning of lexical items must be dominated by the needs and reference skills of the intended target user and the lexicographic functions prevailing in the dictionary. This means adopting lexicographical principles instead of linguistic ones. For example, he lays emphasis on the fact that the "access structure is a lexicographic and not a linguistic device" (64). As a consequence new challenges for both practical and theoretical lexicography are envisaged. For metalexicographers, for instance, Gouws demands devising a new model that allows "a clear and unambiguous identification and description of the different structural components of a dictionary, the different types of entries and the varios data categories" (67). When working on a theoretical level it is important therefore to distinguish between main and sublemmata and to have a clear description of these concepts allowing practical lexicographers interpret and apply the aforementioned distinction. He concludes by indicating that practical and theoretical lexicographers should take another look at the 
way in which sublemmata are selected, presented and treated. In particular, he defends taking a stronger pragmatic approach with less attention to linguistic ordering principles and more to the implementation of user-driven lexicographic criteria.

In "Semantic aspects of reversal of a set of bilingual dictionaries" (71-79), Veisbergs describes a project that will result in compiling a new Latvian-English dictionary by reversing the definition entries of many printed English-Latvian dictionaries. The project is carried out in two stages. The first stage included reversing an English-Latvian dictionary as well as many English-Latvian terminological dictionaries and "imposing this material on the existing entries of the Latvian-English dictionary (Veisbergs 2001), thus enlarging the material" (73). The second stage consists of adding new entries from reversed, mainly terminological sources. After commenting on some of the problems encountered, he concluded by indicating that this way of augmenting existing bilingual dictionaries may be worth the effort, especially for smaller languages whose lexicographical projects are often not commercially interesting.

Chapters 6 and 7 in Part 3 are devoted to Phraseology in Dictionaries. In "Idiomatische Äquivalenzprobleme: Ein ikonoklastischer Zugang" (83-95), Ken Farø discusses the equivalence of idioms in German-Danish dictionaries. He claims that the issue of idioms deserves much more consideration from bilingual lexicographers. In his view, lexicographers base interlingual idiom "pairs" on very shaky foundations, as the two factors usually considered for taking the decision on interlingual idiom pairs are of little use: 1) component quality and structure of the idioms; 2 ) the lexicographer's intuition. The former is very difficult to implement as there is no consensus on what the structure of an idiom is. The second is no longer appropriate, as current lexicographical practices tend to select lemmata on corpus data. Thus, he argues that pragmatic factors, rather than structural similarities, should be the deciding factor in establishing idiom equivalence. He discusses this problem and points out possible solutions with some German-Danish dictionaries.

The second contribution by Erla Hallsteinsdóttir describes the advantages of electronic dictionaries over printed ones in representing idioms. In "a bilingual electronic dictionary of idioms" (97-106), Hallsteinsdóttir presents the initial results of a research project on bilingual lexicography and phraseology at the University of Iceland. The results discussed in this paper include (a) the evaluation of the potential and advantages of electronic dictionaries in comparison to printed dictionaries, and (b) how that potential is exploited to represent the lexicographical content in the German $\leftrightarrow$ Icelandic dictionary of idioms. Hallsteinsdóttir uses the term idiom as a kind of umbrella term for a variety of phraseological units described in the dictionary. After presenting the software used, the article enumerates briefly the lexicographical potential of 
the computer regarding dictionary structure and database organization, access to the dictionary, and dictionary components and document structure. For example, the simplest form of each idiom was selected as lemma to differentiate and identify the idioms. In sum, Hallsteinsdóttir shows some ways in which the lexicographical advantages of the computer can be exploited in a bilingual electronic idiomatic dictionary.

Part 4, which consists of chapters 8 and 9, deals with LSP Lexicography: "Bringing corporate dictionary design into accord with corporate image. From words to messages and back again" (109-117), by Patrick Leroyer, and "Design of a function-based internet accounting dictionary" (119-135) by Sandro Nielsen and Lise Mourier. Leroyer analyzes a number of new theoretical developments and planned practical solutions in the field of corporate lexicography, described as "the scientific study and development of corporate dictionaries for knowledge and communication purposes - internally as well as externally - that are genuinely made to fulfil the needs of the users as well as of the corporation itself" (109). He adds that corporate lexicography should be added to other types of LSP dictionaries, and that it can contribute to the development of a general theory of lexicography. He illustrates his point with data extracted from the corporate website of NEG Micon, a Danish manufacturer of wind turbine technology. In particular, Leroyer presents two new message-dependent dictionary functions: the message planning dictionary function, and the message transcription dictionary planning, classified as knowledge-oriented and communicative-oriented respectively. The former aims at helping the user acquire, check or share knowledge about message planning policy through online message queries. The latter aims at helping the user in the process of transcribing and coining a specific message into text through online access to document database. He concludes by suggesting that knowledge-oriented "functions must now include knowledge of corporate communication planning, while communication-oriented functions must now also include message-dependent functions" (116).

Chapter 9 is devoted to the design of a function-based internet dictionary. Nielsen and Mourier argue that the traditional definition of a dictionary needs to be replaced by a lexicographic approach that focuses on the significant features of a dictionary: its function(s), lexicographic data, and structures. Consequently, they define a dictionary as "a lexicographic reference work that has been designed to fulfil one or more functions, contains lexicographic data supporting the function(s), and contains lexicographic structures that combine and link the data in order to fulfil the function(s)" (121). They add that this definition applies to printed, electronic and Internet dictionaries, and that it also applies to existing, planned and imaginary dictionaries alike. For example, it applies to the Danish-English accounting dictionary, developed at the Centre for Lexicography, Aarhus School of Business, which has been compiled as a 
combined bilingual and extra-linguistic dictionary to satisfy user needs based on a functional approach. This means that this dictionary offers data concerning correct language as well as accounting information. In sum, the Danish Accounting Dictionary (www.regnskabsordbogen.dk) is unique because it is the first electronic Internet accounting dictionary combining several data types relevant to the needs of the user group in function-related situations: definitions of accounting terms, grammatical information, Danish collocations and phrases with English translations, cross-references to other relevant-information, etc. In this way "the dictionary meets the requirements of a state-of-the-art electronic bilingual Internet LSP dictionary" (134).

Part 5 comprises 4 chapters on different topics related with Dictionaries and the User. In Chapter 10, "What's so good or bad about advanced EFL dictionaries?" (139-145), Ilan J. Kernerman considers the qualities and drawbacks of monolingual dictionaries for advanced learners of English. Kernerman states bluntly that the paper aims at questioning "the purportedly superior characteristics of monolingual Dictionaries for Advanced-level Learners of English as a foreign language, hence DALE" (139). To that end, Kernerman mentions some "bad" features or practices of these dictionaries. They stem from the tradition defended by these dictionaries that record home English varieties instead of English as a Lingua Franca (ELF), a more adequate variety because it is culturally neutral and therefore enables speakers of any language to have a common ground with each other. For example, the use of corpora for recording real English does not solve the problem as these corpora do not record ELFs but home English varieties. More to the point, DALE have insistently ignored that their users "rely primarily on their own mother tongues as a prime source of reference on the world. DALE are still conceived according to circumstances of the past, when English was learnt mainly for literary (or tourist) purposes" (141). Finally, DALE are the tip of the iceberg of a huge EFL industry powered by English teachers and scholars. The former recommend the use of DALE, although most of these teachers often know little about dictionaries, have not the means to assess them and to determine which dictionary is most suitable for each learner group, and do not train their students in dictionary use. The latter discuss them in conferences and journals adding feedback to the 'industry'. In sum, in spite of their benefits - the setting of higher standards for modern lexicography, the application of up-to-date and innovative methods of language analysis and pragmatics, and the creation of quality contents and products - the main drawbacks of DALE are the following: (i) they are becoming role models for everything else, (ii) they ignore the users' L1, (iii) their design and presentation may necessitate skills that many dictionary users lack, and (iv) they rely on unreliable corpora which do not provide "the English that is really needed or wanted by its users" (142). 
In Chapter 11, "Glimpses into receptive dictionary use: Proficient learners' perspective. Rationale for the research perspective" (147-164), Renata Szczepaniak addresses the topic of receptive dictionary use by advanced students. She conducts an experiment designed with a view to recreating the natural situation faced by MA students at the School of English, Adam Mickiewicz University. In particular, she investigates whether dictionary use significantly improves comprehension scores and the results can be explained in view of learner- and dictionary-related factors. The study reports on extracting data from creative idiom variants, as these guarantee the adequate level of task difficulty and thus "boost the likelihood of consultation" (150). Her results indicate that the inhability to locate creative idiom variants by advanced students is due to two main factors: insufficient attention on the part of the students and imprecise definitions by lexicographers, in this study the compilers of the Longman Dictionary of Contemporary English (3rd ed.).

Grammar in learner's dictionaries is the subject of analysis in Chapter 12. Geart van der Meer focuses on the "big five" in his paper "The learner's dictionaries and grammar. A comparison" (165-181). In particular, van der Meer studies the way in which the five major English learner's dictionaries have presented and discussed the syntactic or morphological behaviour of words known to cause troubles to foreign learners: (i) some/any; (ii) a; (iii) the; (iv) me; (v) she; (vi) hardly; (vii) ill; (viii) sick; (ix) number, and (x) which/that. He concludes that learner's dictionaries have serious problems in incorporating grammatical information adequately, that they are not very systematic in their treatment, either because they do not always use the same terminology or because they are not "conversant with English formal grammar" (180). He concludes by offering some interesting proposals for future editions of English learner's dictionaries: a clear policy on how much specific terminology is allowed, how much grammar should be included in the dictionary, how this information is to be presented. Finally, he left unresolved an intriguing question: "should we prompt the users more explicitly to go to the dictionary for this kind of grammatical information or restrict ourselves and leave this kind of information to the reference grammars?" (180-181).

Herbert Ernst Wiegand proposes a new definition of the term dictionary article in chapter 13 "Neuere Aspekte einer Theorie und Typologie von Wörterbuchartikeln und ihre Praxisrelevanz" (183-200). His point of departure assumes that although many synonyms exist for the term dictionary article, neither general-language dictionaries nor technical dictionaries dealing with linguistics include it as a lemma. In addition, he also claims that the definitions given in dictionaries of lexicography are also misleading. To overcome this drawback, Wiegand proposes a new definition based on a new theory of dictionary structures. In particular, he focuses on the relationship of dictionary 
article with terms such as accessible entry, data accessibility, etc. in order to offer not only a better definition of dictionary article but also its importance for dictionary typologies.

Part 6 is devoted to Etymology, History and Culture in Lexicography. It consists of 6 chapters by scholars from different geographical places and lexicographical traditions. In Chapter 14, "Lexicographers as borrowers - The importance of being CAMP" (203-215), Arleta Adamska-Salaciak deals with the lack of interlingual equivalence. The problem she poses, which has been the object of much research in translation- and lexicographical-related publications, is the existence of anysomorphism among languages. Bilingual lexicographers, for example, spend a lot of time and effort trying to circumvent the problem "of lack of target language (TL) equivalents for the source language (SL) items" (203). A possible solution is the possibility of borrowing the SL word, which is discussed in detail in this paper in connection with the problems involved in sanctioning such potential loans by the authors and editors of bilingual dictionaries. Adamska-Salaciak illustrates her points with reference to the word camp with examples of recent loans from English into Polish. She concludes that borrowings are to be defended in most occasions, and should be used, especially when the TL speakers are familiar with them. Although she does not go further in her analysis, her last remark is very important for specialized lexicography. Specialized translators tend to incorporate borrowings into the TL with little or no hesitation at all (Montero-Martínez/Fuertes-Olivera/García de Quesada, 2001).

Chapter 15 corresponds to the plenary lecture given by Henning Bergenholtz and Sven Tarp "Politik und Sprachpolitik in der Lexicographie" (217-240). They emphasize two main ideas, which connect lexicographic research with other paradigms. The first idea is that although lexicography and language policy have a long history, they have both gained increased academic attention during the last 25 years. For example, research dealing with Critical Discourse Analysis has also shown the limits of linguistic research or, put it differently, that 'language' can be approached from many different perspectives, some of them without any connection with linguistics. Since the late 1990s, Bergenholtz and Tarp have made their point on where the line between lexicography and linguistics must be drawn (see Bergenholtz/Tarp 2002, 2003, 2004, and Tarp 2008 for an extension on this idea). They also illustrate why connecting lexicography with linguistics is very harmful for the development of lexicography. The second main idea, also hinted at in Bergenholtz/Gouws (2006), comments on the role lexicography can have in some language policy decisions, specifically adequate for making a distinction between a general, a specific and a selecting language policy, as they show in this paper.

Chapter 16 is very specific. In "Revising German Etymologies in the Oxford 


\section{4}

English Dictionary" (241-257), Andreas Gröger shows in which respect the etymologies of English loanwords from German have been improved in the revised third edition of the Oxford English Dictionary. In particular he demonstrates the progress made from the second to the third edition by comparing selected entries from OED3 with their predecessors in OED2. For the purposes of this paper he distinguishes four categories of OED3 entries on German loanwords. The first group comprises entries which already were entries in OED2. Although their etymology has not changed significantly, the style of their presentation is more consistent and gives much more detailed information than OED2. The second group contains nested entries in OED2 which have now been upgraded to main entries and consequently have been given full etymology. The third group consists of entries entirely new to OED3, many of whom come from fields such as politics, food and culinary culture, or medieval German culture. Their etymologies are usually transparent and draw on standard German etymologies in dictionaries. Finally, the last group, the most interesting one, consists of entries which are main entries in both OED2 and OED3 and whose etymologies have improved considerably.

In Chapter 17, Marcin Overgaard Ptaszyński focuses on difficulties with identification and extraction of usage information in 18th century dictionaries. In "Extracting usage information from 18th century English-Danish and DanishEnglish dictionaries" (259-276), Ptaszyński analyzes four English $\leftrightarrow$ Danish dictionaries in order to determine (1) what kind of data can be identified as usage information, and (2) how it can be classified. The task of identification is problematic. First, none of the dictionaries has a rigid system of marking usage information (for example, they did not signal regional or social usage). Second, in all the dictionaries, misprints and mistranslations are rather common. Third, some of the information given is very cryptic and obscure. Lastly, controversies regarding the nature of the subject field label and the regional label have not been solved until today. To solve these problems, Ptaszyński adopts Landau's (2001) typology as a starting point, and reports extensively on the different methods used in each dictionary analyzed. His analysis, for example, allows him to comment that the task of identifying and classifying usage information is more difficult in the first Danish-English dictionary than in the first English-Danish one. Finally, he mentions an important caveat: the possible solutions offered to identifying and classifying usage information are of limited applicability and demand the compilation of corpora of 18th century Danish and English to make the solutions offered more credible.

Roda P. Roberts comments that dictionaries are not only linguistic tools but also cultural objects in chapter 18, "Dictionaries and culture" (277-297). She considers different perspectives on and aspects of culture: national culture, transnational culture, and subculture; After examining what different dictionaries 
(two English monolinguals and two bilingual English-French dictionaries) say regarding their coverage of culture and how the different types of culture are presented in each dictionary, she concludes that the number of cultural words is not very high and that their treatment in the dictionaries analyzed is not as systematic or complete as it should be. She proposes better methods of communicating cultural content, not in the form of cultural notes but "using the various lexical information categories found in the entries" (296).

The book concludes with the plenary lecture given by Arne Zettersten: the so-called Otto Jespersen Memorial Lecture of 2004. After emphasising that Otto Jespersen was also a lexicographer who wrote for Salmonsen's encyclopaedia, and manifested his interest in lexicography by writing the Preface to Pitman's International English Dictionary, Zettersten discusses future aspects of English-based bilingual lexicography in "Glimpses of the future of Englishbased lexicography" (299-318). The future of the English language is related to factors such as the emergence of various types of regional standards, its role as a lingua franca, (it will lead to the emergence of World Standard Spoken English (WSSE) with different varieties), and its presence in the Internet, especially relevant for dictionaries and encyclopaedias. Regarding English lexicography, the above factors will influence dictionary making, characterised by the emergence of processes such as 'globalization', 'localization', 'bilingualization', semibilingualization', 'nationalization', 'regionalization', 'thematization', and 'electronicization' (McArthur 1999). Zetterstem advances that it is under the category 'electronicization' that "we should place one of the keys to the prospective expansion of dictionary-making" (309). This category combines electronic dictionaries and advanced corpus linguistics, as the CD-ROM version of the OED (1999) and the online edition of the same dictionary (2000) show. Moreover, the near future will bring to the fore a new technology which will revolutionalize book printing and dictionary making: electronic paper. This technology, for example, will allow dictionaries for special purposes "to store new words and expressions automatically, not by printing a new edition once in a while, but just by sending new information continually to your electronic paper dictionary" (314). In sum, there will exist an immense number of dictionaries in the future, "not necessarily in the conventional paper formats, but in electronic versions of many kinds" (314).

As said at the beginning, Gottlieb and Mogensen manage to synthesise the contribution and establish some overall coherence by grouping the articles in very well-selected parts. These offer a rather complete picture of today's lexicographic research. In addition, the subject index cross-refers between the different chapters allowing a quick glimpse of the issues mentioned. Congratulations to the editors for it. 


\section{References}

Bergenholtz, Henning/Gouws, Rufus H. 2006: How to do policy with dictionaries. In Lexikos 16, 13-45.

Bergenholtz, Henning/Tarp, Sven 2002: Die Moderne Lexikographische Funktionslehre. Diskussionsbeitrag zu neuen und alten Paradigmen, die Wörterbücher als Gebrauchsgegenstände verstehen. In Lexicographica. International Annual for Lexicography $18,253-263$.

Bergenholtz, Henning/Tarp, Sven 2003: Two Opposing Theories: On H.E. Wiegand's Recent Discovery of Lexicographic Functions. In Hermes. Journal of Linguistics 31, 171-196.

Bergenholtz, Henning/Tarp, Sven 2004: The Concept of Dictionary Usage. In Nordic Journal of English Studies 3, 23-36.

Landau, S. 2001: Dictionaries. The Art and Craft of Lexicography. Cambridge: Cambridge University Press (2nd edition).

McArthur, T. 1999: Living Words. Language, Lexicography and the Knowledge Revolution. Exeter: Exeter University Press.

Montero Martínez, S./Fuertes-Olivera, Pedro A./García de Quesada, M. 2001: The translator as 'language planner': syntactic calquing in an English-Spanish translation of Chemical Engineering. In META 46 (4), 687-698.

Tarp, Sven 2008: Lexicography in the Borderland between Knowledge and nonKnowledge. General Lexicographical Theory with Particular Focus on Learner's Lexicography. (Lexicographica Series Maior). Tübingen: Niemeyer.

Veisbergs, A. 2001: The New Latvian English Dictionary. Tiga: EAI.

Pedro A. Fuertes-Olivera 